\title{
A new primer for metabarcoding of spider gut contents
}

\author{
Denis Lafage ${ }^{1,2}$ (D) | Vasco Elbrecht ${ }^{3,4}$ (D) | Jordan P. Cuff $5^{5}$ (D) | Dirk Steinke \\ Peter A. Hambäck ${ }^{6}$ (D) | Ann Erlandsson ${ }^{1}$ (D)
}

\author{
${ }^{1}$ Department of Environmental and Life \\ Sciences/Biology, Karlstad University, \\ Karlstad, Sweden \\ ${ }^{2}$ UMR ECOBIO, Université de Rennes 1, \\ Rennes, France \\ ${ }^{3}$ Centre for Biodiversity Genomics, \\ University of Guelph, Guelph, ON, Canada \\ ${ }^{4}$ Centre for Molecular Biodiversity Research, \\ Zoological Research Museum Alexander \\ Koenig, Bonn, Germany \\ ${ }^{5}$ School of Biosciences, Cardiff University, \\ Cardiff, UK \\ ${ }^{6}$ Department of Ecology, Environment \\ and Plant Sciences, Stockholm University, \\ Stockholm, Sweden

\section{Correspondence} \\ Denis Lafage, Department of Environmental \\ and Life Sciences/Biology, Karlstad \\ University, Universitetsgatan 2, Karlstad \\ 65188, Sweden. \\ Email: lafage.denis@gmail.com \\ Funding information \\ RIVEM Group (Karlstad University); \\ University of Guelph's Canada First \\ Research Excellence Fund project Food from \\ Thought
}

\begin{abstract}
As a key predator group, spiders have received a lot of attention by food web ecologists. The difficulty involved in studying their diet has led to the use of new technologies such as metabarcoding of gut contents. The amplification of a broad range of spider prey without amplifying spiders themselves is challenging. Until now, an efficient universal primer for this purpose was not available. We developed a novel forward primer (NoSpi2) targeting the COI gene. The primer was designed not to amplify spiders of Pardosa genus while amplifying most other invertebrates. NoSpi2 was tested together with the reverse primer BR2 in silico, in vitro on single specimens of prey and spiders, on mock and malaise trap communities, and in an ecological application. In silico evaluation predicted high primer bias for Pardosa species and more generally for spiders of the oval calamistrum clade (Lycosidae and closely related species) and low bias for other invertebrates. These results were confirmed by in vitro tests. Additionally, some spider families were not amplified contrary to our expectations. We demonstrated a high efficiency for the primer pair NoSpi2/BR2 which recovered $94 \%$ of taxa in the mock community and $85 \%$ of the taxa detected by the best invertebrate primer pair known for the malaise trap community. The field experiment showed that Lycosidae (Hygrolycosa, Pardosa, Piratula, Trochosa) DNA is not amplified by NoSpi2/BR2. It demonstrated a broad range of detectable prey species (12 orders, 67 families, 117 species). The ability of NoSpi2/BR2 primer to reliably amplify prey species, without amplifying any predator DNA, makes it an ideal choice for gut content analysis for lycosid species and related species, even enabling the homogenization of entire specimens without dissection. Given that the detected prey species included other spiders and carabid beetles, this primer could be also used to study intraguild predation.
\end{abstract}

\section{KEYWORDS}

diet, gut content metabarcoding, lycosidae, molecular diet analysis, prey detection 


\section{1 | INTRODUCTION}

The ecological interactions of spiders, the most abundant terrestrial arthropod predator group found on every life-supporting landmass, are pivotal in many ecological networks (Riechert \& Lockley, 1984; Turnbull, 1973). As such, they have received a lot of attention by food web ecologists of diverse fields including pest control (Holland et al., 2016), pollutant transfers (Kraus et al., 2016; Walters, Otter, Kraus, \& Mills, 2018), and cross-ecosystem fluxes (Lafage et al., 2019). Spiders feed on predigested fluids of their prey, restricting field studies of spider diet to direct observation, stable isotope analysis, and molecular analysis (Birkhofer et al., 2017; Pompanon et al., 2012; Symondson, 2002). The inherent bias and the laborious nature of direct observation have led to the increased use of molecular techniques to investigate spider diet, of which DNA metabarcoding is currently among the most accurate and efficient for analysis of polyphagous generalist diets (Piñol, Senar, \& Symondson, 2018).

General metabarcoding-based analyses of diet require PCR primers that amplify a broad range of potential prey species, but ideally without amplifying predator DNA. Given the degraded nature of gut content or fecal DNA in comparison with the relatively intact DNA of the predator, the latter can outcompete prey DNA in both PCR and sequencing (Vestheim \& Jarman, 2008). The selection of primers is thus the most critical step for dietary metabarcoding studies (Piñol et al., 2018). Many studies use primer combinations that target specific species (Boreau de Roincé, Lavigne, Mandrin, Rollard, \& Symondson, 2013; Greenstone \& Shufran, 2003; Kuusk, Cassel-Lundhagen, Kvarnheden, \& Ekbom, 2008), while others focus on a limited number of closely related groups (Chapman, Schmidt, Welch, \& Harwood, 2013; Hambäck, Weingartner, Dalén, Wirta, \& Roslin, 2016; Hosseini, Keller, Schmidt, \& Li, 2011). While this approach does eliminate amplification of predator DNA, it also requires preexisting knowledge of the diet and reduces the possibility of finding unexpected prey species.

Many studies employ blocking probes, which are predator-specific oligonucleotides that bind to the DNA without extension thereby inhibiting predator amplification (Piñol, San Andrés, Clare, Mir, \& Symondson, 2014; Vestheim \& Jarman, 2008). This can, however, also block closely related prey species and increase amplification bias (Piñol et al., 2014). Other ways to reduce predator DNA include extraction from feces (Sint, Thurner, Kaufmann, \& Traugott, 2015), spider webs (Xu, Yen, Bowman, \& Turner, 2015), or regurgitates. However, these methods either reduce the concentration and quality of DNA relative to gut content extraction
(Agustí et al., 2003) or are not possible due to the fluid-feeding behavior of spiders (Kamenova et al., 2018; Waldner, Sint, Juen, \& Traugott, 2013). The amount of predator DNA in spider gut content extractions can also be limited by extraction of just the abdomen, which has a higher proportion of prey DNA, but nevertheless a majority of the extracted DNA will be from the predator (Krehenwinkel, Rödder, \& Tautz, 2015). Similarly, size selection with magnetic beads can be used to limit the amount of intact longer predator DNA present in an extract, leaving only shorter degraded prey DNA (Krehenwinkel et al., 2015), but this removal is based wholly on size and may limit the prevalence of more recently ingested prey and does not remove degraded predator DNA. A better approach would be to use primers which do not amplify the DNA of the predator while still amplifying prey DNA. Lineagespecific primers have previously been designed for multiplex amplification of different prey lineages (Krehenwinkel et al., 2019), but no single primer pair has yet been developed for universal amplification of spider prey while avoiding predator amplification.

In the present study, a novel forward PCR primer was designed to amplify spider prey DNA from spider gut content extracts without amplifying spider predator DNA. We specifically targeted Pardosa spiders (but we also investigated phylogenetically closely related species) which belongs to one of the most diverse and common spider groups (Piacentini et Ramírez, 2019). This primer together with a previously designed reverse primer is relevant for future metabarcoding-based analyses of spider diet.

\section{2 | METHODS}

\section{1 | Primer development and in silico evaluation}

Mitochondrial cytochrome c oxidase subunit 1 (COI) sequences for 15 freshwater invertebrate groups (Vamos, Elbrecht, \& Leese, 2017) and one spider genus (Pardosa) were downloaded and clustered using the "PrimerMiner" package v0.18 (Elbrecht \& Leese, 2017a). All following analyses were run in R 3.6 (R Core Team, 2019). Sequences were aligned in Geneious 8.1.7 (Kearse et al., 2012) using MAFFT v7.017 (Katoh, 2002). PrimerMiner's "selectivetrim" function was used to trim $26 \mathrm{bp}$ of the $\mathrm{HCO}$ and $25 \mathrm{bp}$ of the LCO binding sites, and the alignment for each group was visualized with PrimerMiner to visually identify suitable primer binding sites. Sites conserved among target spider prey taxa but differing in Pardosa sequences were selected, and a primer was designed based on the most optimal combination of sites (Table 1 and Figure 1). The resulting forward primer (NoSpi2) (Table 1) contains a high base degeneracy and binds

TAB LE 1 Primer characteristics as determined with Primer3 2.3.7 implemented in Geneious v2019.0.4 with default settings

\begin{tabular}{|llllll} 
Primer & Sequence $\left(5^{\prime}-\mathbf{3}^{\prime}\right)$ & Source & Average $\operatorname{Tm}\left({ }^{\circ} \mathrm{C}\right)$ & Average GC (\%) & Length $(\mathbf{b p})$ \\
\hline NoSpi2 & TTYCCHCGWATAAAYAAYATAAG & This study & 51.9 & 29.7 & 23 \\
\hline BR2 & TCDGGRTGNCCRAARAAYCA & $\begin{array}{c}\text { Elbrecht and Leese } \\
(2017 \mathrm{~b})\end{array}$ & 59.0 & 49.2 & 20 \\
\hline
\end{tabular}




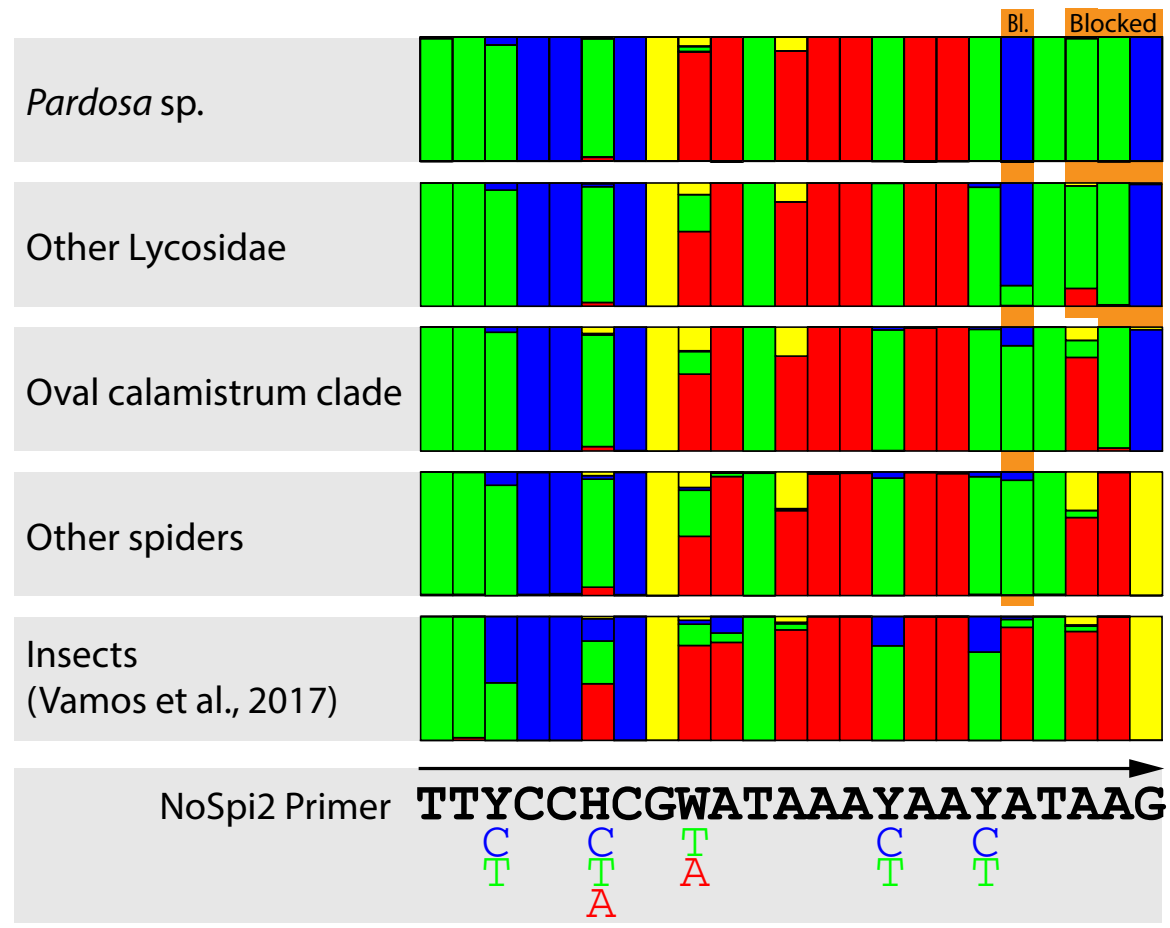

FIGURE 1 Bar plot showing NoSpi2 binding site variability of Pardosa sp., spiders of the oval calamistrum clade, other spider families, and other insects, generated with PrimerMiner. Amplification of spiders of the genus Pardosa and the oval calamistrum clade is expected to be unlikely, due to mismatches at the $3^{\prime}$ end of the NoSpi2 primer. Insect data from Vamos et al. (2017), base composition, green: thymine, blue: cytosine, red: adenine, yellow: guanine, blocked positions highlighted in orange

at position 233,255 of the COI Folmer region (Folmer, Black, Hoeh, Lutz, \& Vrijenhoek, 1994), taking advantage of sequence polymorphisms to enable amplification of target prey species and avoiding amplification of spiders of the genus Pardosa. Amplicon length in combination with the reverse primer BR2 (Table 1) (Elbrecht \& Leese, 2017b) was $403 \mathrm{bp}$.

PrimerMiner was also used to evaluate the primer pair (NoSpi2 and BR2) against alignments of 30 aquatic and terrestrial invertebrate groups and 103 spider families, using default tables for mismatch scoring. As a reference, penalty scores were also computed for the standard barcoding primers LCO1490 and HCO2198 (Folmer et al., 1994).

\section{2 | In vitro evaluation}

In vitro evaluation of the primer pair was performed using two approaches. First, we tested the primer pair on single individuals of potential prey and spiders and on mix of prey and spider DNA. The second approach consisted in testing the primer pair by metabarcoding on a known MOC community (to assess the percentage recovery of species) and on a large and very diverse malaise trap sample (to compare its performance to the best know primer pair for arthropods).

The primer pair was tested in vitro on 6 freshwater and 13 terrestrial invertebrate families (total of 28 species), and 20 spider families (32 species) separately (Appendix S1 and S2). Freshwater invertebrates were selected from samples collected in 2017 from four Swedish rivers using drift nets. Spiders were selected from samples collected in 2017 in the riparian zone of the same four Swedish rivers using a vacuum sampler. Terrestrial invertebrates were selected from samples collected in 2016 in the United Kingdom from arable crops via vacuum sampler, and from decaying beech wood via hand sorting. For herbivorous invertebrates, whole bodies were used, and for predators only legs to restrict possible amplification of gut contents. To investigate possible competitive effects (interference of predator DNA with amplification of prey DNA), sample mixes with equal DNA concentrations (39 $\mathrm{ng} / \mu \mathrm{l}$ ) of starved Lycosidae (Pardosa amentata) and Collembola (Poduridae) or Trichoptera (Limnephiliidae) or Plecoptera (Leutridae) were also tested. In addition, DNA extracts from a starved Lycosidae (Pardosa amentata) at a concentration of $90.8 \mathrm{ng} / \mu \mathrm{l}$ supplemented with Trichoptera (Limnephiliidae) DNA in a decreasing concentration (lowest tested addition $0.007 \mathrm{ng} / \mu \mathrm{l}$ ) were analyzed.

DNA extraction of tissue samples was performed using the QIAamp DNA Micro Kit (Qiagen), following manufacturer instructions. For amplification, the combination of NoSpi2 (Table 1) and BR2 was used (Elbrecht \& Leese, 2017b). PCRs were carried out in $25 \mu \mathrm{l}$ reaction volumes containing $2 \mu \mathrm{l}$ of DNA extract, $12.5 \mu \mathrm{l}$ of PCR Multiplex kit (Qiagen), and $2.5 \mu \mathrm{l}$ of each primer (at $10 \mu \mathrm{M}$ ). Thermocycler conditions were as follows: initial denaturation at $95^{\circ} \mathrm{C}$ for $15 \mathrm{~min} ; 30 \mathrm{cycles}$ of $30 \mathrm{~s}$ at $94^{\circ} \mathrm{C}, 90 \mathrm{~s}$ at $48^{\circ} \mathrm{C}$, and $90 \mathrm{~s}$ at $720^{\circ} \mathrm{C}$; and a final extension for $10 \mathrm{~min}$ at $72^{\circ} \mathrm{C}$. Positive amplifications were confirmed by visual inspection of PCR products in $2 \%$ agarose gels. For positive amplifications, $P C R$ products were purified using ExoSAP-IT ${ }^{\mathrm{TM}}$ PCR Product Cleanup Reagent (Thermo Fisher Scientific). In case of negative amplification, a second PCR with LCO1490/HCO2198 primers was run using the same conditions (different annealing temperature: $40^{\circ} \mathrm{C}$ ) to ensure that the sample contained amplifiable DNA. Purified PCR products (positive samples with NoSpi2/BR2 and positive samples with LCO1490/HCO2198) were then Sanger-sequenced 
and the resulting sequences processed using the sangeranalyse $R$ package (v. 0.1) https://github.com/roblanf/sangeranalyseR. Lowquality ends of sequences were automatically trimmed based on their quality (default cutoff of 0.0001). Subsequently, forward and reverse sequences were merged into a consensus sequence. If the quality of one of the sequences was low, only the other sequence was used. Consensus sequences were queried against NCBI GenBank using the blastn algorithm (Camacho et al., 2009) to retrieve species identity.

In order to assess the arthropod detection efficiency of the primer pair, it was also used to metabarcode an insect mock sample (Braukmann et al., 2018) and a malaise trap sample from Ontario, Canada, both previously tested with 21 primer sets (Elbrecht et al., 2019). A two-step PCR was used to amplify and tag the DNA fragments. The first PCR was performed in $25 \mu \mathrm{l}$ reaction volumes containing $1 \mu \mathrm{l}$ of DNA extract (12.5 ng), $12.5 \mu \mathrm{l}$ of PCR Multiplex plus kit (Qiagen), $0.5 \mu \mathrm{M}$ of each primer (NoSpi2 + BR2), and DNA-free water. The conditions for these PCRs were as follows: initial denaturation at $95^{\circ} \mathrm{C}$ for $5 \mathrm{~min}$; 30 cycles of $30 \mathrm{~s}$ at $95^{\circ} \mathrm{C}, 30 \mathrm{~s}$ at $48^{\circ} \mathrm{C}$, and $50 \mathrm{~s}$ at $72^{\circ} \mathrm{C}$; and a final extension of $5 \mathrm{~min}$ at $72^{\circ} \mathrm{C}$. The second PCR was performed using fusion primers in $25 \mu \mathrm{l}$ reaction volumes: $1 \mu \mathrm{l}$ product from PCR1, $12.5 \mu \mathrm{l}$ of PCR Multiplex kit (Qiagen), $0.2 \mu \mathrm{M}$ of each primer (P7_NoSpi2 CAAGCAGAAGACGGCATACGAGATGTGACTGGAGT TCAGACGTGTGCTCTTCCGATCTCTGATTYCCHCGWAT AAAYAAYATAAG combined with mock sample: P5_BR2_F, malaise sample: P5_BR2_X, Elbrecht \& Steinke, 2018). The second PCR conditions were as follows: initial denaturation at $95^{\circ} \mathrm{C}$ for $5 \mathrm{~min} ; 20 \mathrm{cycles}$ of $30 \mathrm{~s}$ at $95^{\circ} \mathrm{C}, 30 \mathrm{~s}$ at $48^{\circ} \mathrm{C}$, and $2 \mathrm{~min}$ at $72^{\circ} \mathrm{C}$; and a final extension of $5 \mathrm{~min}$ at $72^{\circ} \mathrm{C}$. PCR products were normalized and pooled using Sequal prep (Thermo Fisher Scientific). Primer dimer was subsequently removed using SPRIselect cleanup according to the manufacturer protocol (0.76× SPRIselect used) (Beckman Coulter). The final library contained 96 additional samples of mostly malaise samples and macrozoobenthos kick samples. Sequencing was carried out by the AAC Genomics Facility at the University of Guelph, Canada, on an Illumina MiSeq using the 600 v3 cycle kit with $5 \%$ PhiX spike in. As fusion primer inline tags were used, indexing was skipped and an additional $16 \mathrm{bp}$ was added to the first read, leading to paired-end sequencing of $316+300$ bp length. Bioinformatic processing was done following Elbrecht et al. (2019) using the JAMP pipeline.

\section{3 | Field experiment}

To ascertain its performance in an ecological application, the primer pair was used to amplify spider gut DNA from a field experiment conducted in 2018. Lycosid spiders (Hygrolycosa, Pardosa, Piratula, and Trochosa) were sampled at three riparian sites along the Klarälven River (Sweden). Samples were collected weekly between May 15 and June 19. In each location, spiders were collected from recently flooded areas $(n=20)$ and nonflooded areas $(n=10)$. Individuals were collected using clean forceps and stored individually in $99.6 \%$ ethanol before freezing at $-20^{\circ} \mathrm{C}$.

Each adult was identified to species level before sterile removal of its abdomen for DNA extraction using the QIAamp DNA Micro Kit, as described above. Extra care was taken to avoid contamination: each spider was manipulated in a sterile petri dish and dissected with sterilized forceps and blades. Each step of the follow-up procedures such as DNA extraction, PCR mixes, and PCR product detection and isolation was also performed at separate locations to avoid contamination. To allow multiplex sequencing of the samples, we followed a two steps protocol: A first PCR was run to allow detection and amplification of prey DNA and to prepare sequencing by adding Illumina adpators. A second PCR was run to allow dual tagging of the samples. The first PCR was performed with the primer pair NoSpi2/BR2 extended with universal Turesq Illumina adaptors (33 and $21 \mathrm{bp}$, respectively) using the PCR conditions described (see in vitro evaluation part). Positive amplifications were confirmed by visual inspection of PCR products in $2 \%$ agarose gels. Samples exhibiting bands of the expected size were purified using Agencourt AMPure XP beads following manufacturer specifications (Beckman Coulter). DNA concentration of the cleaned PCR products was determined using a Qubit fluorometer (Thermo Fisher). A second PCR was performed to barcode the samples with dual indexes ( 13 forward $\times 10$ reverse) extended with Illumina adapters (Hugerth et al., 2014). PCRs were carried out in $25 \mu \mathrm{l}$ reaction volumes containing $2 \mu \mathrm{l}$ of the cleaned PCR product, $12.5 \mu$ l of KAPA Taq ReadyMix (2x) (Sigma-Aldrich), $1 \mu \mathrm{l}$ of each primer (at $10 \mu \mathrm{M}$ ), and $8.5 \mu \mathrm{l} \mathrm{H}_{2} \mathrm{O}$. Thermocycler conditions were as follows: an initial denaturation at $98^{\circ} \mathrm{C}$ for $2 \mathrm{~min} ; 10$ cycles of $20 \mathrm{~s}$ at $98^{\circ} \mathrm{C}, 30 \mathrm{~s}$ at $62^{\circ} \mathrm{C}$, and $30 \mathrm{~s}$ at $72^{\circ} \mathrm{C}$; and a final extension for 2 min at $72^{\circ} \mathrm{C}$. PCR product concentrations were measured using a Qubit fluorometer before equimolar pooling $(20.1 \mathrm{ng} / \mu \mathrm{l})$. The pooled product was then purified using Agencourt AMPure XP beads following manufacturer specifications (Beckman Coulter). The DNA library was sequenced in a flow cell on an Illumina MiSeq v3, PE $2 \times 300$, at the Science for Life Laboratory, Sweden (www. ScilifeLab.se).

Sequences were processed using the "dada2" package (Callahan et al., 2016) in R. The pipeline includes demultiplexing, filtering, trimming, dereplication, correction of errors, merging of forward and reverse sequences, and clustering into amplicon sequence variant (ASV). All ASVs produced were screened against BOLD (Ratnasingham \& Hebert, 2007). Sequences with no match were subsequently queried against NCBI GenBank. Sequences were attributed at species level with a similarity match $\geq 98 \%$, to the genus level with a similarity match $\geq 95 \%$, to the family level with a similarity match $\geq 90 \%$, and to the order level with a similarity match $\geq 85 \%$ (Elbrecht, Vamos, Meissner, Aroviita, \& Leese, 2017). If several species obtained identical similarity, the species with more occurrences in Sweden, based on GBIF data (http://www.gbif.org/), was selected. When several ASVs attributed to the same sample referred to the 
same species, the number of differences between sequences was computed. If the number of differences was higher than 50 , the two ASVs were considered two different individuals. Finally, only species which are likely preyed upon by spiders were kept (i.e., bacteria and fungi sequences were discarded).

\section{3 | RESULTS}

\section{1 | Primer development and in silico evaluation}

We designed a primer NoSpi2, which in combination with the primer BR2 (Elbrecht \& Leese, 2017b) targets the Folmer region of the COI gene to generate a sequence of $403 \mathrm{bp}$. In silico evaluation of the primer pair showed high penalty scores for Pardosa species and more generally for all spider families of the oval calamistrum clade (Figure 2) with the strongest values obtained for Lycosidae.

In silico evaluation of the potential prey ( 8 aquatic and 22 terrestrial) showed mostly lower penalty values for NoSpi2 compared with LCO1490 and for BR2 compared with HCO2198 (Figure 3). Among aquatic prey, NoSpi2 and BR2 always had lower penalty scores. Among terrestrial prey, LCO showed lower penalty scores for Embioptera, Strepsiptera, and Archeognatha. BR2 showed lower penalty scores for all other terrestrial prey tested.

\section{2 | In vitro evaluation}

The primer pair NoSpi2/BR2 was evaluated in vitro against 19 invertebrate families ( 28 species) and 20 spider families ( 32 species). It was able to amplify the correct sequence from 25 invertebrate species and 16 spider species (Appendix S3-S9). Only one Hymenoptera species (Tricopria sp.) was not amplified. A sequence obtained from the PCR with LCO1490, identified as Pardosa palustris, was not amplified with NoSpi2/BR2. Two species (one Collembola and one Diptera) could not be identified by sequencing due to the low quality of the reads. The primer pair NoSpi2/BR2 produced contrasting results for spiders (Appendix S3). Several families were not amplified: Lycosidae, Amaurobidae, Clubionidae, Ctenidae, Dysderidae, Oonopidae, Oxyopidae, Philodromidae, Pholicidae, Pisauridae, and Thomisidae. It appears that the Dysderidae sample was also negative with LCO/ HCO2198 suggesting that no amplifiable DNA was present (i.e., no DNA present or PCR inhibition). The Oonopidae and Pisauridae samples were amplified by LCO1490/HCO2198, but the species could not be identified. Among the Linyphiidae species tested, only one sample was not amplified, but the genus mismatch between the morphological and DNA identification suggests a sample error. All mixes for the assessment of a potential inhibitory effect of predator DNA and for the detection threshold of the primer were successfully amplified by NoSpi2/BR2 and provided accurate sequencing results.

The NoSpi2 + BR2 primer set did recover up to $94.17 \%$ of taxa of the mock community, with an average of $310.7(S D=4.22)$ and 352.2 $(S D=2.51)$ taxa recovered at 10,000 and 100,000 read sequencing depth, respectively (subsampled with 1,000 iterations). The same primer set recovered an average of $445.7(S D=9.60)$ and 678.7 $(S D=6.17$ ) taxa of the malaise sample (again at 10,000 and 100,000 read sequencing depth). This recovery represents approximately $10 \%-15 \%$ lower taxon recovery than the currently most efficient universal invertebrate primer pair (e.g., BF3 + BR2) in Elbrecht et al. (2019).

\section{3 | Field experiment}

Among the 388 spiders sampled, 126 led to positive amplification results. The twelve species tested gave positive amplifications. We obtained 540 ASVs corresponding to 12 orders, 67 families, and 117 species (Table 2 and Figure 4, detailed table in Appendix S10 and raw ASVs in Appendix S11). Fifteen spider samples resulted in ASVs that had no match in BOLD nor NCBI GenBank. One ASV corresponded to a spider but not to predator DNA (Clubiona lutescens). No reads corresponded to predator DNA.

\section{4 | DISCUSSION}

In this study, we developed a forward primer (NoSpi2) specifically designed for metabarcoding of gut contents of Pardosa spiders and phylogenetically closely related families of the oval calamistrum clade. Together with the previously designed reverse primer BR2 (Elbrecht \& Leese, 2017b), it detected DNA from a broad range of aquatic and terrestrial arthropods. By using a mock sample and a malaise trap sample from a prior study evaluating primer performance (Elbrecht et al., 2019), we were able to confirm that NoSpi2 recovered about $94 \%$ of taxa. Taking design constraints into account, the primer should detect most prey taxa.

The performance of NoSpi2/BR2 was compared in silico to the barcoding primer pair LCO1490/HCO2198 (Folmer et al., 1994) which it outperformed for metabarcoding all of the groups tested except Embioptera, which are typically tropical insects.

In vitro tests for single specimen were also very successful for prey, with most species being amplified. In some cases, results were less good, but this is likely not only linked to primer performance itself. For example, low matching scores for some chironomids are very likely the result of the underrepresentation of inland chironomids in GenBank and BOLD (Ekrem, Willassen, \& Stur, 2007). Nevertheless, a poor performance of the primer pair on the species tested cannot be excluded. As expected, NoSpi2/ BR2 in vitro tests for spiders showed no amplification for Pardosa and some members of the oval calamistrum clade. Only the amplification of Piratula hygrophila was contrary to our expectation, but Sanger sequencing revealed that the DNA originated from a very common Linyphiidae (Neriene montana), demonstrating the ability of our primer pair to detect intraguild predation among spiders. Similarly, the amplification of Diaea dorsata was unexpected, but Sanger sequencing again demonstrated that the DNA originated 
FIGURE 2 Summary of the phylogenetic tree of the world's spider clades/families from Wheeler et al. (2016). Colors correspond to penalty scores calculated with PrimerMiner for NoSpi2. The higher the penalty score, the lower the likelihood of amplification

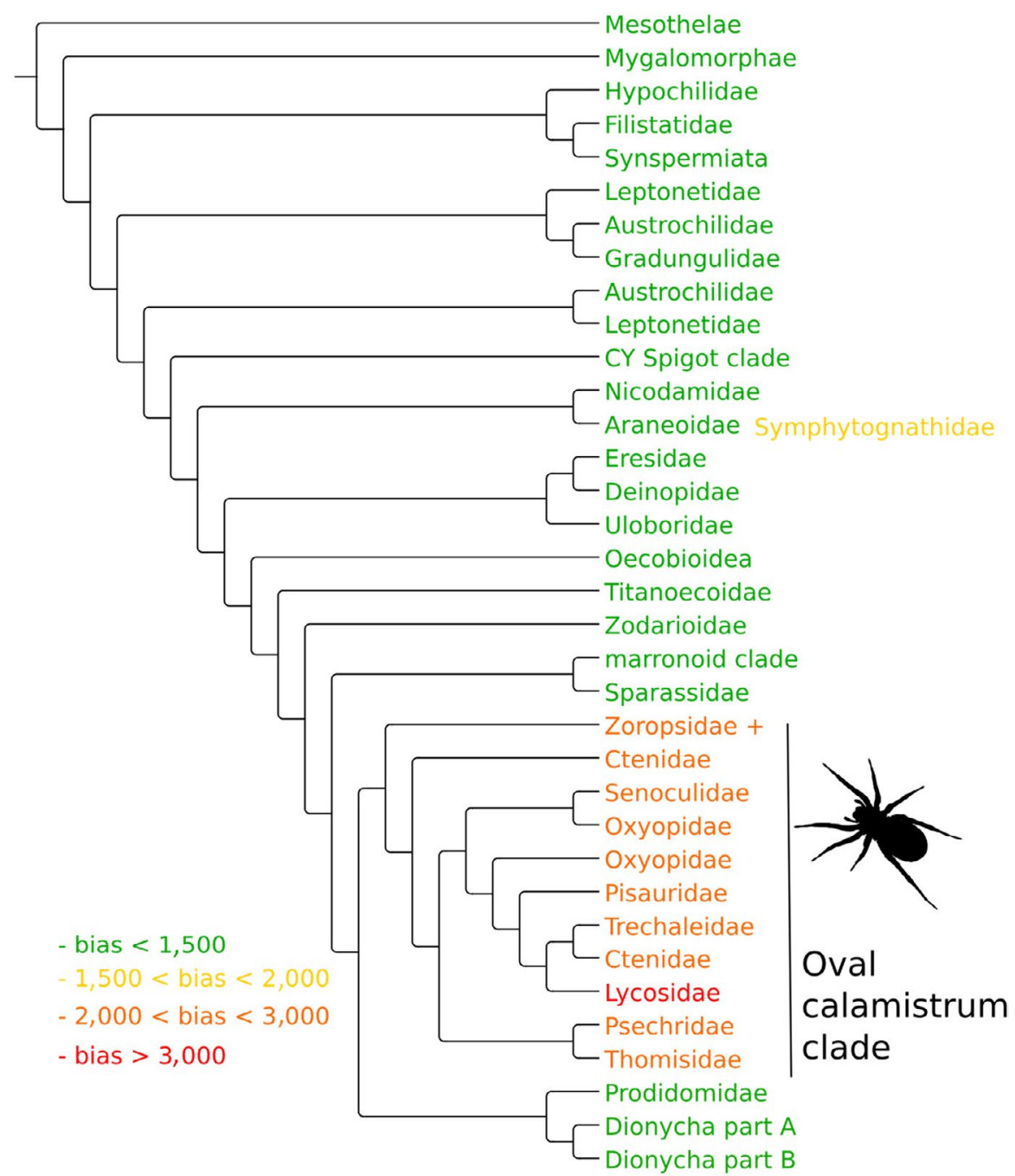

from a prey species: Sialis fuliginosa (Megaloptera). This result further demonstrates the ability of NoSpi2/BR2 to amplify prey DNA without strong amplification of predator DNA. The detection of prey is surprising as only DNA from legs was used, but spider digestive caeca extend into femurs making the detection of prey possible, even when using only legs. We expected members of the families Amaurobidae, Clubionidae, Oonopidae, Philodromidae, and Pholcidae to be amplified by NoSpi2/BR2 given their low primer bias value $(<320)$. This was not the case; however, only one sample was tested per family. More tests are required to verify the capacity of NoSpi2/BR2 to amplify these families. Dysderidae were neither amplified with NoSpi2/BR2 nor amplified with LCO1490/HCO2198. The low bias values (306 for NoSpi2 and 6 for $\mathrm{HCO}$ ) suggest the presence of PCR inhibitors or DNA nucleases in the sample. In vitro tests with different mixes of spider and prey (Trichoptera) suggested no inhibitory effect or lower detection threshold through the inclusion of predator DNA. Indeed, prey was successfully amplified in all mixes and was identifiable to species level with matches greater than $99 \%$, even at very low concentrations in the $\operatorname{mix}\left(2.8^{-6} \mathrm{ng} / \mu \mathrm{l}\right)$.

Our metabarcoding test of the primer pair against a mock community demonstrated a very satisfying recovery of $94.14 \%$ of species. The mock community only included species from families supposed to be amplified by the primer pair. Future user must keep in mind that within each family around $6 \%$ of the species might not be detected. The opposite is true for spiders: within each family not supposed to be amplified, some species might be. The metabarcoding test on a malaise trap showed that while not amplifying Pardosa spiders, the primer pair performed well compared with the best primer pair known for malaise trap metabarcoding. Indeed, it detected only $15 \%$ fewer species.

The field test confirmed that NoSpi2/BR2 can detect a large number of arthropod species (up to 12 orders and 117 species). Interestingly, no predator DNA was amplified, confirming that there is no amplification for the tested Lycosidae species (genera tested: Pardosa, Trochosa, Hygrolycosa, Xerolycosa, and Pirata) using NoSpi2.

Studies focusing on spider diet in natural habitats using metabarcoding are rare. Wirta, Weingartner, Hambäck, and Roslin (2015) found Pardosa glacialis to consume mainly Diptera and Lepidoptera in the High Arctic. Hambäck et al. (2016) also found Diptera as the main prey of Pardosa prativaga followed by Lepidoptera, Coleoptera, and Heteroptera in the Baltic shoreline. In both cases, the authors used primers designed to amplify specifically Diptera and Lepidoptera, 
Coleoptera

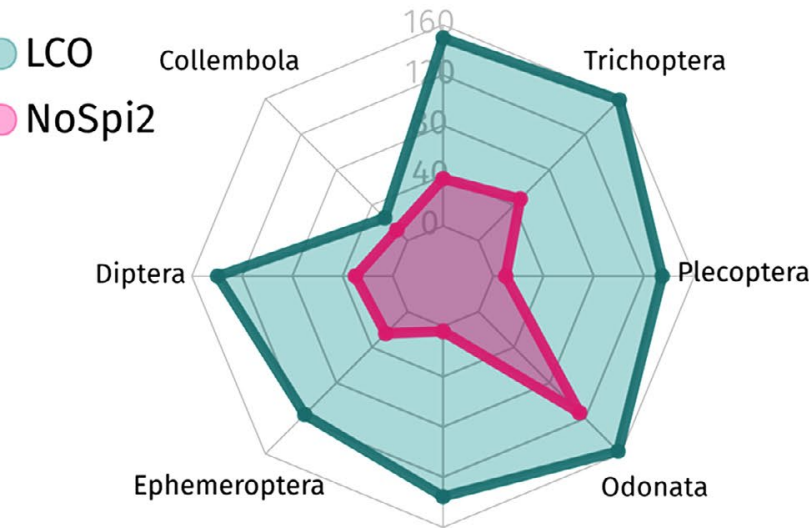

Megaloptera

Coleoptera

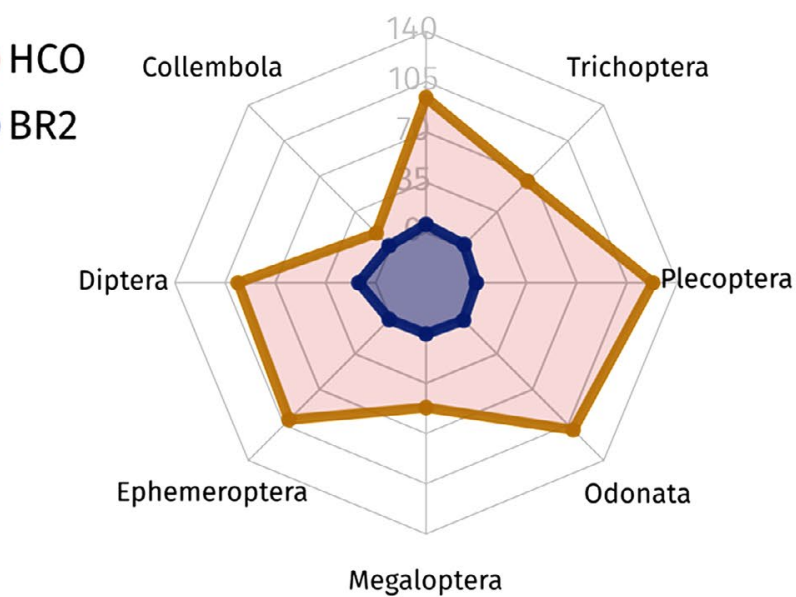

Aquatic prey
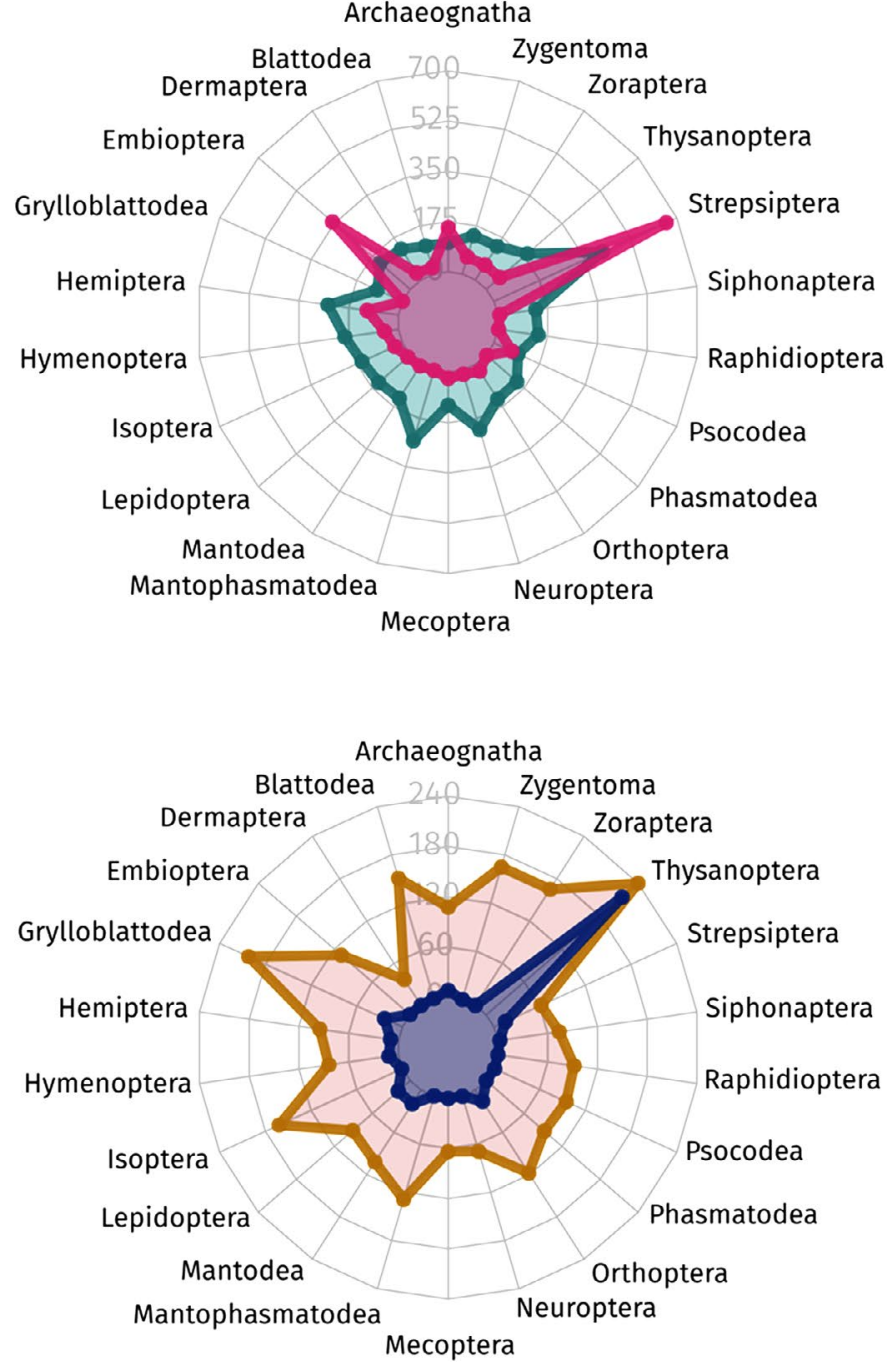

Terrestrial prey

FIGURE 3 Radar charts of penalty scores for each forward and reverse primer. Scores are computed using PrimerMiner (Elbrecht \& Leese, 2017a). Low scores correspond to high amplification efficiency

TABLE 2 Summary table showing the number of species and reads for each order found in 126 spider gut contents

\begin{tabular}{|lcr|}
\hline Class or order & Number of species & Number of reads \\
\hline Acari & 3 & 7,706 \\
\hline Araneae & 1 & 1,027 \\
\hline Coleoptera & 5 & 33,063 \\
\hline Collembola & 4 & 6,568 \\
\hline Diptera & 42 & 242,192 \\
\hline Hemiptera & 32 & 116,518 \\
\hline Hymenoptera & 14 & 137,023 \\
\hline Lepidoptera & 6 & 16,838 \\
\hline Opiliones & 2 & 521 \\
\hline Stylommatophora & 1 & 48 \\
\hline Thysanoptera & 2 & 43 \\
\hline Trichoptera & 2 & 4,256 \\
\hline
\end{tabular}

potentially resulting in an underestimation of other orders. The main orders constituting Lycosid diets in our study were Diptera, Hemiptera, Hymenoptera, and Lepidoptera. Interestingly, spiders, harvestmen, and carabid beetles were also found in spider gut contents which confirm the potential of NoSpi2 for the investigation of intraguild predation, which has often been documented among spiders and for carabid beetles feeding on spiders (Davey et al., 2012; Lang, 2003; Sitvarin \& Rypstra, 2014). Although coleopterans have been reported as spider prey (Hambäck et al., 2016), predation of carabid beetles by spiders is less commonly reported than the opposite (but see: Krehenwinkel, Kennedy, Pekár, \& Gillespie, 2017; Roubinet et al., 2018; Sint, Kaufmann, Mayer, \& Traugott, 2019; Staudacher et al., 2018).

Snail (Stylommatophora) DNA was also detected in spider gut content, showing that despite gastropods generally being considered carabid and harvestmen prey, they are indeed a constituent of the diet of spiders (Nyffeler \& Symondson, 2001). 


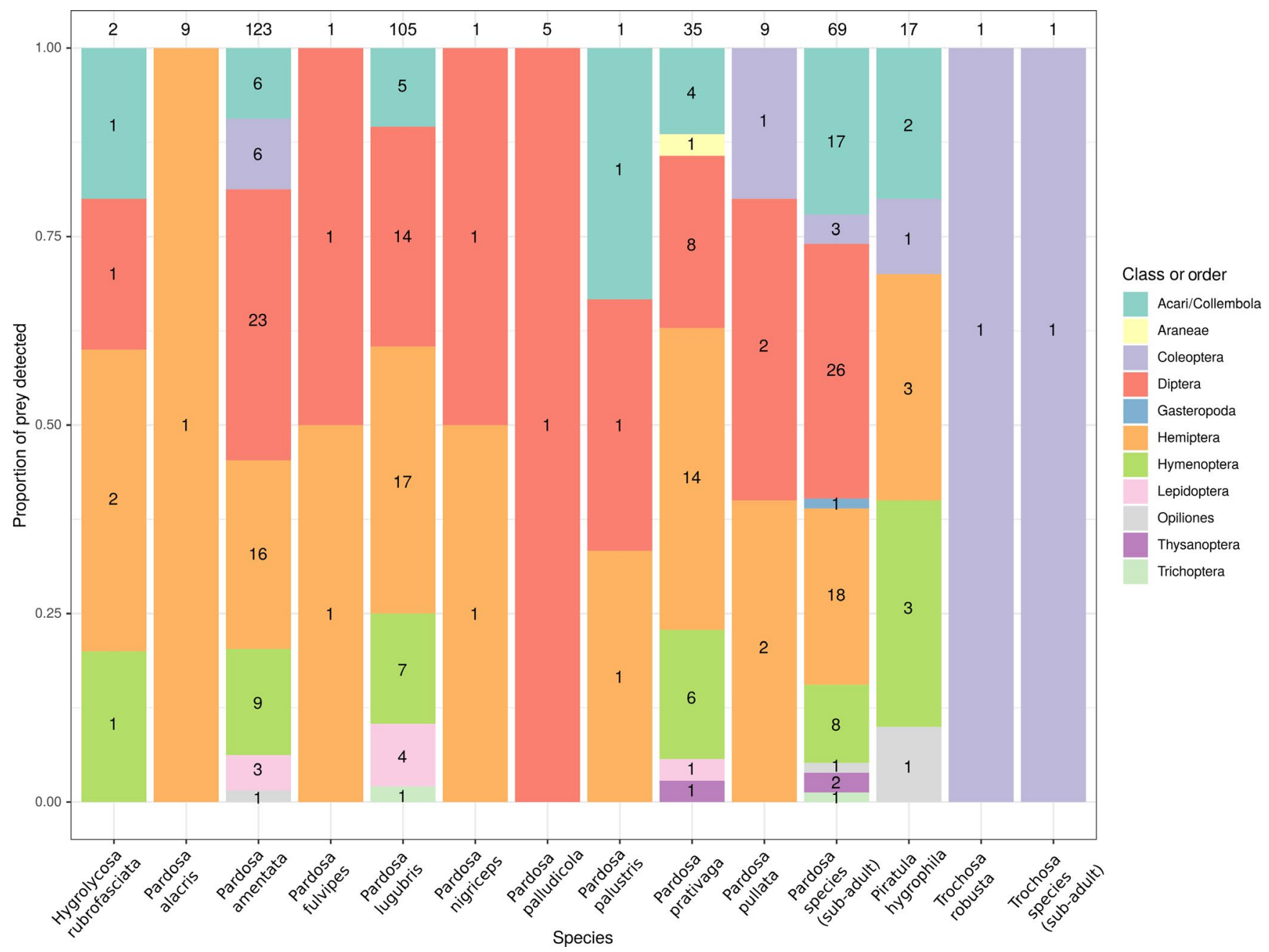

FIGURE 4 Proportion of prey orders detected per spider species. Numbers within bars represent the total number of ASVs per species. Numbers above the bars show the number of individuals tested per species

Despite these very promising results, the fragments generated by NoSpi2/BR2 are relatively long (403 bp). This length ensures a high taxonomic resolution, but it could also limit DNA detectability (Symondson, 2002) due to the higher likelihood of missing shorter degraded sequences (Deagle, Eveson, \& Jarman, 2006; Symondson, 2002). Further studies, particularly feeding experiments, could help to determine the dynamics of DNA degradation enhancing our understanding of spider diet.

\section{5 | CONCLUSION}

Molecular techniques that enable the simple and accurate analysis of spider diet are of great importance for studies investigating the impact of environmental change on ecological processes affecting the most abundant arthropod predators. The primer NoSpi2 developed and extensively validated for this study is ideal for gut content analysis of predator spider species of the genus Pardosa and should perform well for other species of the oval calamistrum clade. It is enabling dietary and biological control studies as well as intraguild predation studies. NoSpi2 amplifies a large number of prey but not the predator species and thereby renders dissection unnecessary because an entire homogenized spider can be used as sample.

\section{ACKNOWLEDGMENTS}

We also thank the RIVEM Group (Karlstad University) for funding the in vitro and field tests. V.E. and D.S., as well as the metabarcoding experiments, were supported by funding through the University of Guelph's Canada First Research Excellence Fund project Food from Thought.

\section{CONFLICT OF INTEREST}

None declared.

\section{AUTHOR CONTRIBUTIONS}

D.L. conceived the idea and led the project. V.E. designed the primer. D.L., V.E., J.C., P.A.H., and A.E. contributed to the laboratory work, 
data processing, and analyses. D.L., J.C., and V.E. wrote the draft manuscript. All authors contributed critically to the drafts and gave final approval for publication.

\section{DATA AVAILABILITY STATEMENT}

Trimmed sequences from the Sanger sequencing (in vitro evaluation) are available under the NOSPI project on BOLD. Raw sequence data from the mock community metabarcoding and malaise sample are available under the SRA accession numbers SRX5975749 and SRX5975748. Data from the complete run with the 96 additional samples not analyzed in this study are available under accession PRJNA546583. Raw sequence data from the field test metabarcoding are available under SRA accession number PRJNA550981. The code used for data analysis is available on GitLab under the project ID: 9419382 (https://gitlab.com/Denis Lafage/nospi).

\section{ORCID}

Denis Lafage (iD https://orcid.org/0000-0002-6205-611X Vasco Elbrecht ID https://orcid.org/0000-0003-4672-7099 Jordan P. Cuff (iD https://orcid.org/0000-0002-0198-4940 Peter A. Hambäck iD https://orcid.org/0000-0001-6362-6199 Ann Erlandsson (iD https://orcid.org/0000-0002-3813-9548

\section{REFERENCES}

Agustí, N., Shayler, S. P., Harwood, J. D., Vaughan, I. P., Sunderland, K. D., \& Symondson, W. O. C. (2003). Collembola as alternative prey sustaining spiders in arable ecosystems: Prey detection within predators using molecular markers. Molecular Ecology, 12(12), 3467-3475. https://doi.org/10.1046/j.1365-294X.2003.02014.x

Birkhofer, K., Bylund, H., Dalin, P., Ferlian, O., Gagic, V., Hambäck, P. A., ... Jonsson, M. (2017). Methods to identify the prey of invertebrate predators in terrestrial field studies. Ecology and Evolution, 7(6), 1942-1953. https://doi.org/10.1002/ece3.2791

Boreau de Roincé, C., Lavigne, C., Mandrin, J.-F., Rollard, C., \& Symondson, W. O. C. (2013). Early-season predation on aphids by winter-active spiders in apple orchards revealed by diagnostic PCR. Bulletin of Entomological Research, 103, 148-154. https://doi.org/10.1017/ S0007485312000636

Braukmann, T. W. A., Ivanova, N. V., Prosser, S. W. J., Elbrecht, V., Steinke, D., Ratnasingham, S., ... Hebert, P. D. N. (2018). Revealing the complexities of metabarcoding with a diverse arthropod mock community. BioRxiv, 433607. https://doi.org/10.1101/433607

Callahan, B. J., McMurdie, P. J., Rosen, M. J., Han, A. W., Johnson, A. J. A., \& Holmes, S. P. (2016). DADA2: High-resolution sample inference from Illumina amplicon data. Nature Methods, 13(7), 581-583. https ://doi.org/10.1038/nmeth.3869

Camacho, C., Coulouris, G., Avagyan, V., Ma, N., Papadopoulos, J., Bealer, K., \& Madden, T. L. (2009). BLAST+: Architecture and applications. BMC Bioinformatics, 10(1), 421. https://doi. org/10.1186/1471-2105-10-421

Chapman, E. G., Schmidt, J. M., Welch, K. D., \& Harwood, J. D. (2013). Molecular evidence for dietary selectivity and pest suppression potential in an epigeal spider community in winter wheat. Biological Control, 65(1), 72-86. https://doi.org/10.1016/j.bioco ntrol.2012.08.005

Davey, J. S., Vaughan, I. P., Andrew King, R., Bell, J. R., Bohan, D. A., Bruford, M. W., ... Symondson, W. O. C. (2012). Intraguild predation in winter wheat: Prey choice by a common epigeal carabid consuming spiders. Journal of Applied Ecology, 50(1), 271-279. https ://doi.org/10.1111/1365-2664.12008

Deagle, B. E., Eveson, J. P., \& Jarman, S. N. (2006). Quantification of damage in DNA recovered from highly degraded samples - A case study on DNA in faeces. Frontiers in Zoology, 3(1), 11. https://doi. org/10.1186/1742-9994-3-11

Ekrem, T., Willassen, E., \& Stur, E. (2007). A comprehensive DNA sequence library is essential for identification with DNA barcodes. Molecular Phylogenetics and Evolution, 43(2), 530-542. https://doi. org/10.1016/j.ympev.2006.11.021

Elbrecht, V., Braukmann, T. W. A., Ivanova, N. V., Prosser, S. W. J., Hajibabaei, M., Wright, M., ... Steinke, D. (2019). Validation of COI metabarcoding primers for terrestrial arthropods. PeerJ, 7, e7745.

Elbrecht, V., \& Leese, F. (2017a). PrimerMiner: An R package for development and in silico validation of DNA metabarcoding primers. Methods in Ecology and Evolution, 8(5), 622-626. https://doi. org/10.1111/2041-210X.12687

Elbrecht, V., \& Leese, F. (2017b). Validation and development of coi metabarcoding primers for freshwater macroinvertebrate bioassessment. Frontiers in Environmental Science, 5, 1-11. https://doi. org/10.3389/fenvs.2017.00011

Elbrecht, V., \& Steinke, D. (2018). Scaling up DNA metabarcoding for freshwater macrozoobenthos monitoring. Freshwater Biology, 64 380-387. https://doi.org/10.7287/peerj.preprints.3456v4

Elbrecht, V., Vamos, E. E., Meissner, K., Aroviita, J., \& Leese, F. (2017). Assessing strengths and weaknesses of DNA metabarcoding-based macroinvertebrate identification for routine stream monitoring. Methods in Ecology and Evolution, 8(10), 1265-1275. https://doi. org/10.1111/2041-210X.12789

Folmer, O., Black, M., Hoeh, W., Lutz, R., \& Vrijenhoek, R. (1994). DNA primers for amplification of mitochondrial cytochrome c oxidase subunit I from diverse metazoan invertebrates. Molecular Marine Biology and Biotechnology, 3(5), 294-299. https://doi.org/10.1371/journ al.pone.0013102

Greenstone, M. H., \& Shufran, K. A. (2003). Spider predation: Species specific identification of gut contents by polymerase chain reaction. Journal of Arachnology, 31, 131-134. https://doi.org/10.1636/0161-8 202(2003)031[0131:SPSIOG]2.0.CO;2

Hambäck, P. A., Weingartner, E., Dalén, L., Wirta, H., \& Roslin, T. (2016). Spatial subsidies in spider diets vary with shoreline structure: Complementary evidence from molecular diet analysis and stable isotopes. Ecology and Evolution, 6(23), 8431-8439. https://doi. org/10.1002/ece3.2536

Holland, J. M., Bianchi, F. J. J. A., Entling, M. H., Moonen, A.-C., Smith, B. M., \& Jeanneret, P. (2016). Structure, function and management of semi-natural habitats for conservation biological control: A review of European studies. Pest Management Science, 72(9), 1638-1651. https ://doi.org/10.1002/ps.4318

Hosseini, R., Keller, M. A., Schmidt, O., \& Li, D.-M. (2011). Design and assessment of primers to detect insect pests of Brassica crops in the gut contents of arthropod predators. Munis Entomology and Zoology, 6(1), 477-492.

Hugerth, L. W., Wefer, H. A., Lundin, S., Jakobsson, H. E., Lindberg, M., Rodin, S., ... Andersson, A. F. (2014). DegePrime, a program for degenerate primer design for broad-taxonomic-range PCR in microbial ecology studies. Applied and Environmental Microbiology, 80(16), 5116-5123. https://doi.org/10.1128/AEM.01403-14

Kamenova, S., Mayer, R., Rubbmark, O. R., Coissac, E., Plantegenest, M., \& Traugott, M. (2018). Comparing three types of dietary samples for prey DNA decay in an insect generalist predator. Molecular Ecology Resources, 18(5), 966-973. https://doi. org/10.1111/1755-0998.12775

Katoh, K. (2002). MAFFT: A novel method for rapid multiple sequence alignment based on fast Fourier transform. Nucleic Acids Research, 30(14), 3059-3066. https://doi.org/10.1093/nar/gkf436 
Kearse, M., Moir, R., Wilson, A., Stones-Havas, S., Cheung, M., Sturrock, S., ... Drummond, A. (2012). Geneious basic: An integrated and extendable desktop software platform for the organization and analysis of sequence data. Bioinformatics, 28(12), 1647-1649. https://doi. org/10.1093/bioinformatics/bts199

Kraus, J. M., Pomeranz, J. F., Todd, A. S., Walters, D. M., Schmidt, T. S., \& Wanty, R. B. (2016). Aquatic pollution increases use of terrestrial prey subsidies by stream fish. Journal of Applied Ecology, 53(1), 44-53. https://doi.org/10.1111/1365-2664.12543

Krehenwinkel, H., Kennedy, S. R., Adams, S. A., Stephenson, G. T., Roy, K., \& Gillespie, R. G. (2019). Multiplex PCR targeting lineage-specific SNP: A highly efficient and simple approach to block out predator sequences in molecular gut content analysis. Methods in Ecology and Evolution, 10, 982-993. https://doi.org/10.1111/2041-210X.13183

Krehenwinkel, H., Kennedy, S., Pekár, S., \& Gillespie, R. G. (2017). A cost-efficient and simple protocol to enrich prey DNA from extractions of predatory arthropods for large-scale gut content analysis by Illumina sequencing. Methods in Ecology and Evolution, 8(1), 126-134.

Krehenwinkel, H., Rödder, N., \& Tautz, D. (2015). Eco-genomic analysis of the poleward range expansion of the wasp spider Argiope bruennichi shows rapid adaptation and genomic admixture. Global Change Biology, 21, 4320-4332.

Kuusk, A.-K., Cassel-Lundhagen, A., Kvarnheden, A., \& Ekbom, B. (2008). Tracking aphid predation by lycosid spiders in spring-sown cereals using PCR-based gut-content analysis. Basic and Applied Ecology, 9(6), 718-725. https://doi.org/10.1016/j.baae.2007.08.012

Lafage, D., Bergman, E., Eckstein, R. L., Österling, E. M., Sadler, J. P., \& Piccolo, J. J. (2019). Local and landscape drivers of aquatic-to-terrestrial subsidies in riparian ecosystems: A worldwide meta-analysis. Ecosphere, 10(4), e02697. https://doi.org/10.1002/ecs2.2697

Lang, A. (2003). Intraguild interference and biocontrol effects of generalist predators in a winter wheat field. Oecologia, 134(1), 144-153. https://doi.org/10.1007/s00442-002-1091-5

Nyffeler, M., \& Symondson, W. O. C. (2001). Spiders and harvestmen as gastropod predators. Ecological Entomology, 26(6), 617-628. https:// doi.org/10.1046/j.1365-2311.2001.00365.x

Piacentini, L. N., \& Ramírez, M. J. (2019). Hunting the wolf: A molecular phylogeny of the wolf spiders (Araneae, Lycosidae). Molecular Phylogenetics and Evolution, 136, 227-240. https://doi.org/10.1016/j. ympev.2019.04.004

Piñol, J., San Andrés, V., Clare, E. L., Mir, G., \& Symondson, W. O. C. (2014). A pragmatic approach to the analysis of diets of generalist predators: The use of next-generation sequencing with no blocking probes. Molecular Ecology Resources, 14(1), 18-26. https://doi. org/10.1111/1755-0998.12156

Piñol, J., Senar, M. A., \& Symondson, W. O. C. (2018). The choice of universal primers and the characteristics of the species mixture determine when DNA metabarcoding can be quantitative. Molecular Ecology, 28(2), 407-419. https://doi.org/10.1111/mec.14776

Pompanon, F., Deagle, B. E., Symondson, W. O. C., Brown, D. S., Jarman, S. N., \& Taberlet, P. (2012). Who is eating what: Diet assessment using next generation sequencing. Molecular Ecology, 21(8), 19311950. https://doi.org/10.1111/j.1365-294X.2011.05403.x

R Core Team (2019). R: A language and environment for statistical computing. Vienna, Austria: R Foundation for Statistical Computing. Retrieved from http://www.r-project.org

Ratnasingham, S., \& Hebert, P. D. (2007). BOLD: The barcode of life data system (http://www.barcodinglife.org). Molecular Ecology Notes, 7(3), 355-364.

Riechert, S. E., \& Lockley, T. (1984). Spiders as biological control agents. Annual Review of Entomology, 29, 299-320. https://doi.org/10.1146/ annurev.en.29.010184.001503

Roubinet, E., Jonsson, T., Malsher, G., Staudacher, K., Traugott, M., Ekbom, B., \& Jonsson, M. (2018). High redundancy as well as complementary prey choice characterize generalist predator food webs in agroecosystems. Scientific Reports, 8(1), 8054. https://doi. org/10.1038/s41598-018-26191-0

Sint, D., Kaufmann, R., Mayer, R., \& Traugott, M. (2019). Resolving the predator first paradox: Arthropod predator food webs in pioneer sites of glacier forelands. Molecular Ecology, 28(2), 336-347. https:// doi.org/10.1111/mec.14839

Sint, D., Thurner, I., Kaufmann, R., \& Traugott, M. (2015). Sparing spiders: Faeces as a non-invasive source of DNA. Frontiers in Zoology, 12(1), 3. https://doi.org/10.1186/s12983-015-0096-y

Sitvarin, M. I., \& Rypstra, A. L. (2014). The importance of intraguild predation in predicting emergent multiple predator effects. Ecology, 95(10), 2936-2945. https://doi.org/10.1890/13-2347.1

Staudacher, K., Rennstam Rubbmark, O., Birkhofer, K., Malsher, G., Sint, D., Jonsson, M., \& Traugott, M. (2018). Habitat heterogeneity induces rapid changes in the feeding behaviour of generalist arthropod predators. Functional Ecology, 32(3), 809-819. https://doi. org/10.1111/1365-2435.13028

Symondson, W. O. C. (2002). Molecular identification of prey in predator diets. Molecular Ecology, 11(4), 627-641. https://doi. org/10.1046/j.1365-294X.2002.01471.x

Turnbull, A. L. (1973). Ecology of the true spiders (Araneomorphae). Annual Review of Entomology, 18(1), 305-348. https://doi. org/10.1146/annurev.en.18.010173.001513

Vamos, E., Elbrecht, V., \& Leese, F. (2017). Short COI markers for freshwater macroinvertebrate metabarcoding. Metabarcoding and Metagenomics, 1, e14625. https://doi.org/10.3897/mbmg.1.14625

Vestheim, H., \& Jarman, S. N. (2008). Blocking primers to enhance PCR amplification of rare sequences in mixed samples - A case study on prey DNA in Antarctic krill stomachs. Frontiers in Zoology, 5(1), 12. https://doi.org/10.1186/1742-9994-5-12

Waldner, T., Sint, D., Juen, A., \& Traugott, M. (2013). The effect of predator identity on post-feeding prey DNA detection success in soil-dwelling macro-invertebrates. Soil Biology and Biochemistry, 63, 116-123. https://doi.org/10.1016/j.soilbio.2013.03.030

Walters, D. M., Otter, R. R., Kraus, J. M., \& Mills, M. A. (2018). Riparian spiders indicate the magnitude and sources of polychlorinated biphenyl contamination at a large contaminated sediment site. Environmental Toxicology and Chemistry, 37, 2467-2474. https://doi. org/10.1002/etc.4216

Wheeler, W. C., Coddington, J. A., Crowley, L. M., Dimitrov, D., Goloboff, P. A., Griswold, C. E., ... Zhang, J. (2016). The spider tree of life: Phylogeny of Araneae based on target-gene analyses from an extensive taxon sampling. Cladistics, 33, 574-616, https://doi.org/10.1111/cla.12182

Wirta, H. K., Weingartner, E., Hambäck, P. A., \& Roslin, T. (2015). Extensive niche overlap among the dominant arthropod predators of the High Arctic. Basic and Applied Ecology, 16(1), 86-92. https://doi. org/10.1016/j.baae.2014.11.003

Xu, C. C. Y., Yen, I. J., Bowman, D., \& Turner, C. R. (2015). Spider web DNA: A new spin on noninvasive genetics of predator and prey. PLoS ONE, 10(11), e0142503. https://doi.org/10.1371/journal.pone.0142503

\section{SUPPORTING INFORMATION}

Additional supporting information may be found online in the Supporting Information section.

How to cite this article: Lafage D, Elbrecht V, Cuff JP, Steinke D, Hambäck PA, Erlandsson A. A new primer for metabarcoding of spider gut contents. Environmental DNA 2020;2:234-243. https://doi.org/10.1002/edn3.62 